\title{
OUTCOME OF DARNING METHOD OF INGUINAL HERNIA REPAIR
}

\author{
Ayman Essawy $^{(1)}$; Mohamed Ibrahim ${ }^{(1)}$; El Ashraf Mohamed Thabet ${ }^{(1)}$; \\ Moatasem Erfan ${ }^{(2)}$ Ismail Fathi Ismail Mohammed
}

\author{
(1)General Surgery Department, Faculty of Medicine, Fayoum University \\ (2)General Surgery Department, Faculty of Medicine, Misr University For Science and \\ Technology (MUST)
}

Corresponding author: Ismail Fathi Ismail Mohammed

E-mail:esmael.fathi33@gmail.com

Mobile: 01030494010

\begin{abstract}
Background: Inguinal hernia is a common cause of pain in the groin, and the third most important cause of patients requiring hospital emergency services. The diagnosis of an inguinal hernia is usually made through history and physical examination findings. Inguinal hernias may be asymptomatic and found incidentally on routine physical examination. Symptoms of an inguinal hernia may appear gradually over time or develop suddenly, as with incarceration (i.e., the contents of the hernia sac cannot be returned to the abdominal cavity). Repairs can be divided initially into open repairs and laparoscopic repairs. The open repairs can be divided into tissue repairs and prosthetic repairs.
\end{abstract}

Objective: The study aimed to evaluate the polypropylene darning method in the treatment of inguinal hernia assessing complications (especially surgical site infection, postoperative pain, early recurrence rate), and return to normal activities. The patients were followed during the first week postoperatively, two weeks then one month, 3 months and the end of the study (6 months).

Methods: This is a prospective study including 40 male patients admitted to our hospital (Fayoum university hospital) for surgical treatment of inguinal hernia. The study started from the 1st of August 2018 to the 1st of November 2018. The study was approved by the medical ethics committee of the Faculty of Medicine, Fayoum University.

Results: Our study included 40 male patients who were treated surgically by using darning repair, followed up during the first week postoperatively, two weeks then one month, 3 months and 6 months. No recurrence could be detected. Only $7.5 \%$ had wound infection that subsides within 5 days by antibiotic and dressing and $12.5 \%$ had seroma that subsides (within 10 days) spontaneously with antioedematous, hot fomentation and scrotal elevator. The study showed that the mean length of hospital stay among study group was $(27.6 \pm 8.7)$ hours ranged between 24 and 48 hours, in addition to that the short hospital stay of patient reduced the cost and decreased the frequency of hospital acquired infections.

Conclusion: The darning technique is a safe and effective method of inguinal hernia repair. Darn repair thus represents a good alternative to the gold standard (Lichtenstein mesh repair) for primary inguinal hernia especially in poor countries where mesh is not readily available.

KEYWORDS: Darning; Inguinal hernia repair 


\section{INTRODUCTION}

Hernia is defined as a protrusion of a viscus or part of a viscus from the cavity in which it is contained, may be with defect (muscle fascia, foramen magnum, or diaphragm) or no defect (paralytic). There are several predisposing factors leading to the development of hernia like strenuous exercise, lifting heavy weight, chronic cough, constipation, straining at micturition, as all of these lead to weakening of fascia transversalis. Congenital persistence of peritoneo-vaginal canal is still the major cause of inguinal hernia (1)

Among all hernias, inguinal hernia repair is the most common operation undertaken in routine surgical practice with an annual incidence of 13/1000 population of all age ${ }^{(2)}$. Most hernias are detectable on clinical examination. Clinical presentations range from the appearance of a bulge in the groin area, apparent on routine physical examination, to life-threatening presentations due to strangulation of the intestine. Inguinal hernia repair has undergone several modifications

\section{AIM OF THE WORK}

The aim of this study is to evaluate the polypropylene darning method in the treatment of inguinal hernia assessing complications (especially surgical site infection, postoperative pain, early recurrence rate), and

\section{PATIENT AND METHODS}

This is a prospective study including 40 male patients admitted to our hospital (Fayoum university hospital) for surgical treatment of inguinal hernia. The study started from the 1st of August 2018 to the 1st of November 2018. Written and informed consent for surgery were obtained from all patients. The study was approved by the medical ethics committee of the Faculty of Medicine, Fayoum University.

\section{Inclusion Criteria}

since the description of the Bassini technique (3).

The various techniques described are aimed at improving outcome, particularly recurrence rate. The underlying factor identified as a cause of recurrence in most of these methods of repair is the fraying and tearing of the fibers of the inguinal ligament due to the significant amount of tension associated with them ${ }^{(4)}$.

All these repairs were based on the principle of reinforcement of the posterior wall of the inguinal canal with narrowing of internal ring ${ }^{(5)}$.

Darning technique first introduced by Abrahamson and popularized by Moloney is considered to be a relatively tension free through tissue based method of repair. It entails approximation of the inguinal ligament to the conjoint tendon with monofilament nylon 1 beginning from the pubic tubercle to the internal ring and back to the pubic tubercle without forcibly bringing the tissues together with the sutures forming a weave in the posterior wall of the inguinal canal ${ }^{(6,7)}$.

return to normal activities. The patients were followed during the first week postoperatively, two weeks then one month, 3 months and the end of the study (6 months).

Male patient presented with unilateral inguinal hernia with class (1) or (2) according to American society of anesthesia.

\section{Exclusion Criteria:}

\section{1- Recurrent}

\section{2- Bilateral}

3- Patient presented with untreated predisposing factors

4- Other classes of American society of anesthesia than 1 and 2 


\section{Preoperative Assessment}

\section{History:}

Full clinical history with special attention to age, occupation, and special habits of medical importance (drug abuse and/or smoking) were taken from all patients. We asked him in details about onset, course and duration of his groin pain.

In addition to symptoms suggestive of complications such as: vomiting, constipation, abdominal distention and associated medical problems as steroids intake, besides, the past history of previous hernia repair and other operations.

\section{Clinical Examination:}

General examination to rule out systemic diseases. Local groin examination was done to confirm diagnosis, to detect

\section{Details of procedure:}

\section{Anesthesia:}

All patients received spinal anesthesia. All patients were placed in the supine position. Operative field was sterilized by povidoneiodine and toweled up in normal manner.

\section{Incision}

Mark an incision line from the intersection of the index fingers placed superior and lateral to the midpoint of the pubic symphysis to a point $4 \mathrm{~cm}$ horizontal and lateral to this intersection point (transverse incision along the lower crease). The subcutaneous fat was then opened along the length of the incision, and careful hemostasis was achieved by ligating superficial external pudendal and superficial epigastric vessels. Carefully, dissect Scarpa's fascia with electrocautery until the anterior surface of the external oblique aponeurosis is exposed. The external inguinal ring and the lower border of the inguinal ligament were visualized.

Begin the dissection of the external oblique aponeurosis by first making a small incision to expose the underlying internal oblique aponeurosis. Then, continue the dissection using forceps and scissors taking complications and to exclude other swellings. The abdomen was examined for any organomegaly.

\section{Laboratory and radiological evaluation}

Laboratory (Routine) investigations were done for all patients including complete blood count (CBC), ALT, AST, Urea, Creatinine, serum albumin, P.T and blood sugar. Radiological investigations such as abdominal ultrasonography were done to exclude any intra-abdominal concurrent pathology, ECG and plain chest radiography in case of previous history of smoking, bronchial asthma, or clinical signs of chest troubles.

care not to injure the internal oblique aponeurosis. The ilioinguinal nerve, lying underneath the aponeurosis, was identified and safeguarded during this procedure. The superior and inferior flaps of the external oblique aponeurosis were gently freed from the underlying contents of the inguinal canal.

\section{Dissection of spermatic cord}

The next step is to isolate and mobilize the spermatic cord through lifting up and separating from the pubic bone for about $2 \mathrm{~cm}$ beyond the pubic tubercle. The cord structures encircled in the tape was separated from the floor of the inguinal canal up to the internal ring.

\section{Identification and management of hernia sac}

The cord structures and all of the nerves of the inguinal canal had been visualized, the next step was to identify and isolate the hernia sac. The indirect hernia sac is anterolateral to the cord structures and was visualized by dividing the cremaster muscle longitudinally. The hernia sac was identified and separated from the spermatic vessels and 
the vas deferens up to its neck. The neck of the hernia sac was transfixed then divided via vicryl 0 . A high ligation of the proximal sac was done, and the stump was reduced deep underneath the internal ring. The distal sac was left in place; the anterior wall of the distal sac was incised to prevent postoperative hydrocele formation except if dissection of distal end of the sac is difficult, to avoid ischemic orchitis. A direct inguinal hernia is posteromedial to the cord structures. The direct hernia sac was isolated and dissected free. Its contents were reduced, and the peritoneal sac was inverted with plication of fascia transversalis by prolene 2/0. Then darning repair was done (approximation of the inguinal ligament to the conjoint tendon with prolene 1 , beginning from the pubic tubercle to the internal ring and back to the pubic tubercle without forcibly bringing the tissues together with the sutures forming a weave in the posterior wall of the inguinal canal). The stitches were taken at different levels of inguinal ligament to spread the tension between its fibers.

\section{Closure:}

Hemostasis was ensured in the inguinal canal, which was then closed by suturing the two flaps of the external oblique aponeurosis with vicryl 2_0, with care was taken not to injure the underlying ilioinguinal nerve. Suturing was started laterally and continued medially. Subcutaneous tissue was approximated with interrupted sutures (vicryl 3_0) to obliterate any dead space, and the skin was approximated with prolene 3_0 sutures. The operative site was cleaned and a sterile dressing applied. Drain wasn't used at our steps due to less tissue manipulation than other techniques. Skin Stitches were removed 15 days after the operation.

\section{Post-operative care}

All patients received postoperative analgesia (non-steroidal intra muscular once daily) during 1 st and 2 nd postoperative days except 8 patients that had prolonged pain, they received analgesia on demand 2 days postoperative (oral). Evaluation of our technique was done including the following parameters: Aga distribution to recognize if there is correlation with parameter, Incidence of seroma formation was followed by ultrasound, Post-operative fever, pain, wound infection and recurrence.

\section{Statistical Analysis}

Data were collected and coded to facilitate data manipulation and double entered into Microsoft Access and data analysis was performed using Statistical Package of Social Science (SPSS) software version 18 in windows 7. Quantitative data included in the study was first tested for normality by OneSample Kolmogorov-Smirnov test in each study group then inferential statistic tests were selected. In-depended student t-Test used to compare measures of two independent groups of quantitative data. Chi square test to compare two of more than two qualitative groups. Bivariate Pearson correlation test to test association between variables.

\section{RESULTS}

Our study included 40 patients ranged between 20 years and 73 years old with mean age of $(40.92 \pm 0.61)$ (Table 1).

Table (1): Description of age among study group.

\begin{tabular}{|l|c|}
\hline $\begin{array}{c}\text { Age (years) } \\
(\mathrm{n}=40)\end{array}$ & Parameters \\
\hline Mean & 40.92 \\
\hline SD & 0.61 \\
\hline Range & $20-73$ \\
\hline
\end{tabular}

All patients included in the study were medically free without medical history of diabetes mellitus, or hypertension. As regards side of hernia, 22 patients $(55 \%)$ complain hernia on right side, versus 18 patients $(45 \%)$ on left side (Table 2). 
Table (2): Frequency of medical history and side of hernia among study group.

\begin{tabular}{|c|c|c|}
\hline \multirow{2}{*}{$\begin{array}{c}\text { Variables } \\
(\mathrm{n}=40)\end{array}$} & \multicolumn{2}{|c|}{ Frequency } \\
\hline & Number & $\%$ \\
\hline \multicolumn{3}{|l|}{ Medical history } \\
\hline No & 100 & $100 \%$ \\
\hline Yes & 0 & $0 \%$ \\
\hline \multicolumn{3}{|l|}{ Side of hernia } \\
\hline Right & 22 & $55 \%$ \\
\hline Left & 18 & $45 \%$ \\
\hline
\end{tabular}

In our study, there were 3 patients complicated with SSI managed by antibiotic, and dressing then subside after five days; 5 patients complicated with subcutaneous seroma that subsides (within 10 days) spontaneously with anti-edematous drug, hot fomentation and scrotal elevator, finally all patients complain pain (FPS2); relieved after operation with analgesia except 8 patients where pain persisted more than that (Table 4), but all cases show complete recovery with no recurrence after six months follow up among study group (Table 3).

Table (3): Frequency of types of postoperative complication among study group.

\begin{tabular}{|c|c|c|}
\hline \multirow{2}{*}{$\begin{array}{c}\text { Variables } \\
(\mathrm{n}=40)\end{array}$} & \multicolumn{2}{|c|}{ Postoperative Complications } \\
\hline & Number & $\%$ \\
\hline \multicolumn{3}{|l|}{ SSI } \\
\hline No & 37 & $92.5 \%$ \\
\hline Yes & 3 & $7.5 \%$ \\
\hline \multicolumn{3}{|l|}{ Seroma } \\
\hline No & 35 & $87.5 \%$ \\
\hline Yes & 5 & $12.5 \%$ \\
\hline \multicolumn{3}{|l|}{ Pain } \\
\hline No & 0 & $0 \%$ \\
\hline Yes & 40 & $100 \%$ \\
\hline \multicolumn{3}{|l|}{ Recurrence } \\
\hline No & 40 & $100 \%$ \\
\hline Yes & 0 & $0 \%$ \\
\hline
\end{tabular}

According to pain, 32 patients $(80 \%)$ had pain for 2 days only that relieved with analgesia but 7 patients $(17.5 \%)$ had pain for Table (4): Frequency of pain progression among study group.

\begin{tabular}{|l|c|c|}
\hline \multicolumn{1}{|c|}{$\begin{array}{c}\text { Variables } \\
(\mathrm{n}=40)\end{array}$} & \multicolumn{2}{|c|}{ Pain progression } \\
\cline { 2 - 3 } & Number & $80 \%$ \\
\hline Only 2 days & 32 & $17.5 \%$ \\
\hline Two weeks & 7 & $2.5 \%$ \\
\hline Three months & 1 & \multicolumn{2}{c|}{} \\
\hline
\end{tabular}

On the other hand, the mean length of hospital stay among study group was (27.6 \pm 8.7 ) hours ranged between 24 and 48 hours.

As regards duration to return to normal level of activity the mean duration was $(8.4 \pm 4.2)$ days ranged between 7 and 28 days (table 5 ). two weeks and one patient only $(2.5 \%)$ had chronic post-operative pain for 3 months (Table 4).

Table (5): Description of duration of hospital stay and duration to return to normal activity in different study groups.

\begin{tabular}{|l|c|c|c|}
\hline \multicolumn{1}{|c|}{ Variables } & Mean & SD & Range \\
\hline Hospital stay (hours) & 27.6 & 8.7 & $24-48$ \\
\hline Return to normal activity (days) & 8.4 & 4.2 & $7-28$ \\
\hline
\end{tabular}

In our study, there is correlation between age and postoperative complications because most of patients had postoperative complications were old in age, so there is

statistically significant difference as regard post-operative complication (seroma and infection) correlation with age with p-value $<0.05$. 
Additionally, there is correlation between duration needed to return to normal activity and postoperative complications because most of patients had postoperative complications needed more time to return to normal activity ,so there is high statistically significance as regard post-operative complication (seroma and infection) correlation with duration needed to return to normal activity with $\mathrm{p}$ value $<0.05$.

But there isn't correlation between duration of hospital stay and post-operative complication with no statistically significant difference with p-value $>0.05$ because postoperative complication appeared after hospital discharge (Table 6).

Table (6): Comparisons of age, length of hospital stay and duration of return to normal activity in different complication groups (seroma and SSI).

\begin{tabular}{|c|c|c|c|c|c|c|}
\hline \multirow{3}{*}{ Variables } & \multicolumn{4}{|c|}{$\begin{array}{c}\text { Postoperative complication } \\
\text { (seroma and SSI) }\end{array}$} & \multirow{3}{*}{ p-value } & \multirow{3}{*}{ Sig. } \\
\hline & \multicolumn{2}{|c|}{ No $(n=32)$} & \multicolumn{2}{|c|}{ Yes $(n=8)$} & & \\
\hline & Mean & SD & Mean & SD & & \\
\hline Age (years) & 37.3 & 14.5 & 50.4 & 12.2 & 0.01 & $\mathbf{S}$ \\
\hline Hospital stay (hours) & 27.3 & 8.4 & 28.4 & 9.7 & 0.7 & $\mathrm{NS}$ \\
\hline $\begin{array}{l}\text { Return to normal activity } \\
\text { (days) }\end{array}$ & 7 & 0 & 12.1 & 7.1 & $<0.001$ & HS \\
\hline
\end{tabular}

In our study, we observed that the old age patients needed more time to return to work, so there is statistically significant positive correlation with $\mathrm{p}$-value $<0.05$ between duration to return to normal activity with patient age.

In addition to that, we observed that the patients had post-operative complication needed more time to return to work, so there is statistically significant positive correlation with p-value $<0.05$ between number of complications occurs to patients and time needed to return to work.

Finally, younger patient with no complication recovers faster (Table 7). But, there isn't correlation between duration of hospital stay and time needed to return to work.

Table (8): Correlation between duration to return to normal activity with age and length of hospital stay and number of complications among study group.

\begin{tabular}{|l|c|c|c|}
\hline \multirow{2}{*}{ Variables } & \multicolumn{2}{c|}{ Return to normal activity (weeks) } \\
\cline { 2 - 4 } & $\mathbf{r}$ & $\mathbf{p}$-value & Sig. \\
\hline Age (years) & $\mathbf{0 . 3 5}$ & $\mathbf{0 . 0 2}$ & S \\
\hline Hospital stay (days) & 0.09 & 0.6 & NS \\
\hline Number of complications & $\mathbf{0 . 5 0}$ & $\mathbf{0 . 0 0 1}$ & HS \\
\hline
\end{tabular}

\section{DISCUSSION}

In this study we aimed to detect outcome of darning inguinal hernia repair especially postoperative pain, early recurrence, surgical site infection and return to normal activities.

In our study, all patients were treated surgically by using darning repair, followed up during the first week postoperatively then two weeks, one month, 3 months and 6 months.

We excluded patients with bilateral inguinal hernia because laparoscopic method is preferred. We also excluded recurrent hernias as the incidence of chronic pain increase with recurrent cases ${ }^{(8)}$. We also excluded Patients presented with untreated predisposing factors and classes 3,4,5,6 of American society of anesthesia because the recurrence rate and other post-operative complication will be high.

\section{Initially, considering the recurrence} rates, there was no evidence of recurrence during the period of follow. Patients were followed up in outpatient clinic during the first 
week postoperatively then two weeks, one month, 3 months and 6 months.

Additionally, recurrence rate in Olasehind et al ${ }^{(\mathbf{9})}$ study was 0\%. Mean duration of follow-up was 7.5 months. Similar results have been documented in other studies of Chakraborty et al and Jawwad Azeem Khan et al. ${ }^{(\mathbf{1 0 , 1 1})}$.

\section{In another study to Olasehind} recurrence rate was $1.5 \%$ at a mean duration of follow-up of 15 months.

Also, BinBisher Saeed et al. reported a recurrence of $0.8 \%$ f. The follow up period was one year.

Our follow-up period, therefore, is probably not sufficiently long; thus, it is recommended to advocate longer durations of follow-up in subsequent studies ${ }^{(13)}$.

Secondly, regarding the length of hospital stay, the study showed that the mean length of hospital stay was $(27.6 \pm 8.7)$ hours ranged between 24 and 48 hours with no statistically significant difference between patient with and without postoperative complications as regards length of hospital stay.

Nonetheless, these findings are relatively concordant with Jawwad Azeem Khan et $a l^{(\mathbf{1 1 )}}$, where the mean duration of the postoperative hospital stay was 1.05 days.

Another study to BinBisher Saeed et al (13), showed that the mean duration of the postoperative hospital stay was 3 days.

The idea is to encourage the patient for early ambulation and to avoid hospital acquired infection (11). Furthermore; short hospital stay of patient reduces the cost ${ }^{(13)}$.

Our study showed that return to normal activity (walking, stair climbing, eating, bathing, sitting and sleeping),showed a mean duration of $(8.4 \pm 4.2)$ days ranged between 7 and 28 days with high mean among patients with complications, this indicated that patient with complication takes more time to return to normal activity.
Another study to Jawwad Azeem Khan et al. ${ }^{(11)}$, showed a mean duration of 1.04 days to return to normal work.

Moreover, as regard to the surgical site infection, events in our study, there were 3 cases $(7.5 \%)$ with SSI that subsided within 5 days by antibiotic and dressing.

That was nearly the same as the study conducted by Olalekan Olasehind et $a .^{\left(\mathbf{( 1 2}^{2}\right)}$ which showed a surgical site infection of $(4.5 \%) . \%)$ and more than that conducted by Jawwad Azeem Kha et al. (11) whereas Superficial SSI was $0 \%$

On the other hand, seroma or hematoma formation occurred in 5 cases $(12.5 \%)$, that subsided (within 10 days) spontaneously with anti-edematous, hot fomentation and scrotal elevator.

In a study by Olasehindel et al (9) $25.5 \%$ of cases developed hematoma. Wound hematoma and scrotal edema have also been recognized as the commonest complications similar to previous findings with Hussain and Koukourou $^{(\mathbf{1 4 , 1 5})}$.

Another study to Ahmed Khyrallh (16) showed that hematoma occurred in one $(1 \%)$ patient and seroma occurred in four (4\%) patients.

But another study to Gulshan Ali Memon et al. ${ }^{(17)}$ showed that no hematoma or seroma occurred.

Ultimately, chronic groin pain is currently considered an important outcome measure following inguinal hernia repair particularly as it affects the quality of life.

All patients received analgesia postoperative. To measure the severity of pain, a scale from 1-10 was used and patients would be asked how much pain they felt on the scale at the end of 6,12 and 24 hours of the surgery.

In our study, there were post-operative pain for two days to $80 \%$ (32 cases) that subsided with analgesia but there were $17.5 \%$ (7 cases) that had pain for two weeks and $2.5 \%$ (one case only) for three month.

That was nearly the same as the study conducted by Courtney et al ${ }^{(\mathbf{1 8})}$, Olalekan 
Olasehinde et al ${ }^{(12)}$ and Ahmad et al. ${ }^{(19)}$ which showed the incidence of chronic postoperative pain was $3 \%$.

\section{CONCLUSION}

In our study, the darning technique is a safe and effective method of inguinal hernia repair. Darn repair thus represents a good alternative to the gold standard (Lichtenstein

\section{REFERENCES}

[1] Kurzer M, Belsham PA, Kark AE. The Lichtenstein repair for groin hernias. Surg Clin Manzar S. Inguinal hernias, Incidence, complications and management. J Coll Physicians \& Surg Pak 1992; 2:7-9.

[2] Primatesta P,Goldacre MJ. Inguinal hernia repair: incidence of elective and emergency surgery, readmission and mortality. International journal of epidemiology. 1996 Aug 1;25(4):835-9.

[3] Bekker J, Keeman JN, Simons MP, Aufenacker TJ. A brief history of the inguinal hernia operation in adults. Nederlands tijdschrift voor geneeskunde. 2007 Apr;151(16):92431 .

[4] Zsolt B, Csiky M. Recurrence rate in Bassini operation after five years. Magyar sebeszet. 2001 Oct;54(5):3078.

[5] Amid PK. Groin hernia repair: open techniques. World journal of surgery. 2005 Aug 1;29(8):1046-51.

[6] Abrahamson J. Hernias. In: Zinner MJ, editor. Maingot's Abdominal Operations. 10th ed. Conneticut: Appleton and Lange; 1997. p. 479-580.

[7] Moloney GE. Darning inguinal hernias. Arch Surg 1972;104:129-30
The finding of a longer duration of pain and the occurrence of more severe pain in the early post-operative period was quite notable in other studies to Kaynack et al ${ }^{\text {(20) }}$ and Imamuddin et al ${ }^{(\mathbf{2 1})}$.

mesh repair) for primary inguinal hernia especially in poor countries where mesh is not readily available.

[8] Mori T, Souda S, Nezu R, Yoshikawa Y. Results of performing mesh plug repair for groin hernias. Surgery today. 2001 Feb 1;31(2):129-32.

[9] Olasehinde O, Lawal OO, Agbakwuru EA, Adisa AO, Alatise OI, Arowolo OA, Adesunkanmi AR, Etonyeaku AC. Comparing Lichtenstein with darning for inguinal hernia repair in an African population. Hernia. 2016 Oct 1;20(5):667-74.

[10] Chakraborty S, Mukherjee A, Bhattacharya $\mathrm{M}$. Tension-free inguinal hernia repair comparing'darn'with'mesh': A prospective randomized controlled clinical trial. Indian Journal of Surgery. 2007 Mar 1;69(2).

[11] Khan JA, Imaduddin S, Razzak R, Haider S, Zaman J. Darning versus mesh repair for inguinal hernia: when do patients return to normal physical activity. Pak J Surg. 2015;31(3):173-8.

[12] Olasehinde OO, Adisa AO, Agbakwuru EA, Etonyeaku AC, Kolawole OA, Mosanya AO. A 5-year Review of Darning Technique of Inguinal Hernia Repair. Nigerian Journal of Surgery. 2015;21(1):52-5.

[13] Rabee B, Aram FO, Abdulla A. Inguinal hernia repair by darning. 
Yemeni Journal for Medical Sciences. 2009 Dec 1;3:5-.

[14] Hussain A, Aamer N, Asad MM Pakistan armed forces medical journal (2007) 57(1):23-27.

[15] Koukourou A, Lyon W, Rice J, Wattchow DA. Prospective randomized trial of polypropylene mesh compared with nylon darn in inguinal hernia repair. British journal of surgery. 2001 Jul;88(7):931-4.

[16] Khyrallh AA. Lichtenstein procedure versus darn repair in primary inguinal hernia surgery. Al-Azhar Assiut Medical Journal. 2017 Oct 1;15(4):196.

[17] Memon GA, Shah SK. An experience with mesh versus darn repair in inguinal hernias. Pakistan journal of medical sciences. 2017 May;33(3):699.

[18] Courtney CA, Duffy K, Serpell MG, O'dwyer PJ. Outcome of patients with severe chronic pain following repair of groin hernia. British Journal of Surgery. 2002 Oct 1;89(10):1310-4.

[19] Ahmad S, Ahmed N, Singha JL, Rayhan F, Hassan AF, Hossain MA, Islam M. Open Maloney Repair for Adult Inguinal Hernia, 5 Years Experience in A Remote District. Journal of Shaheed Suhrawardy Medical College. 2018 Nov 22;10(1):610.

[20] Kaynak B, Celik F, Guner A, Guler K, Kaya MA, Celik M. Moloney darn repair versus Lichtenstein mesh hernioplasty for open inguinal hernia repair. Surgery today. 2007 Nov 1;37(11):958-60.

[21] Mamuddin B, Sher MS, Iasmeen I, Ghulam S, Rajib AD. Moloney darn repair: versus Lichenstien mesh repair comparison of Cost effectiveness and complications. 2010; 16(1):81-84. 